\title{
Erratum
}

\section{The Validity of Mass Body Temperature Screening with Ear Thermometers in a Warm Thermal Environment}

\section{Tatsuhiko Suzuki, ${ }^{1}$ Koji Wada, ${ }^{2}$ Yuko Wada, ${ }^{1}$ Hideaki Kagitani, ${ }^{1}$ Tetsuya Arioka, ${ }^{1}$ Koji Maeda $^{1}$ and Kenichi Kida ${ }^{1}$}

${ }^{1}$ Terumo Corporation, Tokyo, Japan

${ }^{2}$ Department of Preventive Medicine and Public Health, Kitasato University School of Medicine, Kanagawa, Japan

Tohoku J. Exp. Med., 222: 89-95, 2010.

In the version of this article published in the October issue, 2010, the graphs shown in (a) and (b) of Figure 2 are adversely displayed (page 92). The corrected figure is shown below. The data in each graph remain unchanged.

(a) Cold environment

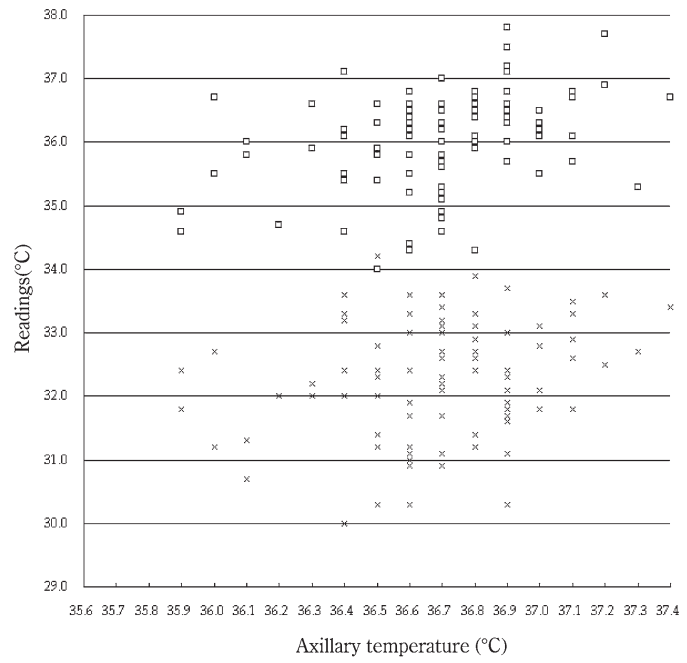

(b) Warm environment

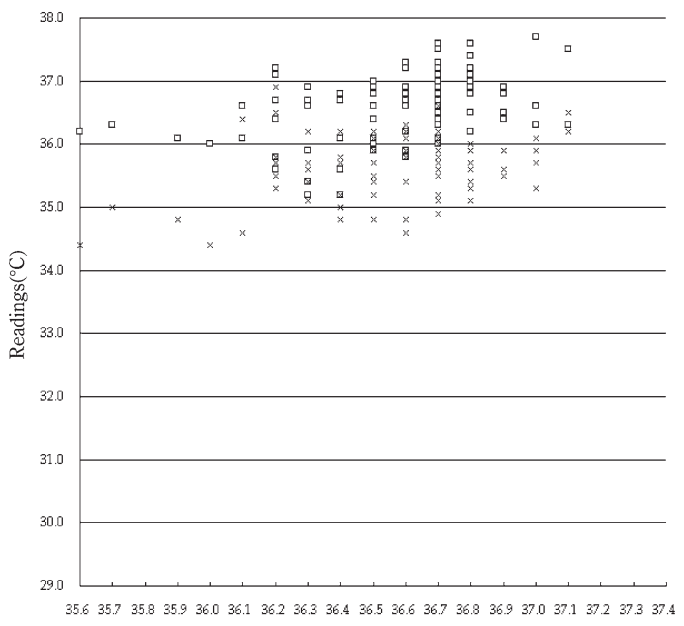

Axillary temperature $\left({ }^{\circ} \mathrm{C}\right)$

Fig. 2. Distribution of ear and facial temperature plotted against axillary temperature in cold and warm environments.

(a) Cold environment (mean ambient temperature was $12.6^{\circ} \mathrm{C}$, mean humidity was $33.0 \%$, and mean wind speed was 1.3

$\mathrm{m} / \mathrm{s}$ ). (b) Warm environment (mean ambient temperature was $20.0^{\circ} \mathrm{C}$, mean humidity was $35.0 \%$, and mean wind speed was $0.0 \mathrm{~m} / \mathrm{s}) . \square$ : Ear temperature; $\mathrm{x}$ : facial temperature. 